\title{
Full vaccination coverage among children aged 12-23 months in Ethiopia: a systematic review and meta-analysis
}

Daniel Bekele Ketema ${ }^{1 *}$ (D), Moges Agazhe Assemie ${ }^{1}$, Alehegn Aderaw Alamneh², Muluneh Alene', Kassahun Yawukal Chane ${ }^{3}$, Yoseph Merkebe Alamneh ${ }^{4}$, Molla Yigzaw Birhanu ${ }^{5}$ and Animut Alebel ${ }^{6,7}$

\begin{abstract}
Background: Vaccination is one of the most cost-effective means of public health interventions to prevent childhood deaths from infectious diseases. Although several fragmented studies have been conducted concerning full vaccination coverage among children aged 12-23 months in Ethiopia, the pooled estimate has not been determined so far. Therefore, this systematic review and meta-analysis aims to estimate the pooled prevalence of full vaccination coverage among children aged 12-23 months in Ethiopian.

Methods: To find potentially relevant studies, we systematically searched five major databases (i.e., PubMed/ MEDLINE, CINAHL, EMBASE, Google Scholar, and Science Direct). This review included community based crosssectional studies reported in English language; had good quality, and published from the 1st of January 2000 to the 20th of November 2019. Data were analyzed using Stata ${ }^{\mathrm{TM}}$ Version 14.1 software. The pooled estimates with 95\% confidence intervals (Cls) were presented using forest plots. Higgins and Egger's tests were used to assess heterogeneity and publication bias, respectively. Primary estimates were pooled using a random effects metaanalysis model.

Results: Of the total of 851 identified articles 21 studies involving 12,094 children met the inclusion criteria and were included in this meta-analysis. The included studies sample size ranged from 173 to 923 . The lowest proportion of full vaccination coverage was reported from Afar Region [21\% (95\% Cl: 18, 24\%)], whereas the highest proportion of full vaccination coverage was reported from Amhara Region [73\% (95\% Cl: 67, 79\%)]. The overall prevalence of full vaccination coverage among children in Ethiopia was 60\% (95\% Cl: 51, 69\%).

Conclusions: Our finding suggested that six in every 10 children in Ethiopia were fully vaccinated. However, this finding is much lower than the World Health Organization recommended rate. Moreover, high regional variations in terms of full vaccination coverage across the country was observed. Therefore, a special attention should be given to improve the overall childhood vaccination coverage.
\end{abstract}

Keywords: Vaccination coverage, Systematic review, Meta-analysis, Ethiopia

\footnotetext{
* Correspondence: danibekele2009@gmail.com

'Department of Public Health, College of Health Sciences, Debre Markos University, P.O. Box 269, Debre Markos, Ethiopia

Full list of author information is available at the end of the article
}

(C) The Author(s). 2020 Open Access This article is licensed under a Creative Commons Attribution 4.0 International License, which permits use, sharing, adaptation, distribution and reproduction in any medium or format, as long as you give appropriate credit to the original author(s) and the source, provide a link to the Creative Commons licence, and indicate if changes were made. The images or other third party material in this article are included in the article's Creative Commons licence, unless indicated otherwise in a credit line to the material. If material is not included in the article's Creative Commons licence and your intended use is not permitted by statutory regulation or exceeds the permitted use, you will need to obtain permission directly from the copyright holder. To view a copy of this licence, visit http://creativecommons.org/licenses/by/4.0/. The Creative Commons Public Domain Dedication waiver (http://creativecommons.org/publicdomain/zero/1.0/) applies to the data made available in this article, unless otherwise stated in a credit line to the data. 


\section{Background}

Although the world made remarkable progress in reducing under-five mortality from 12.6 million deaths in 1990 to 5.4 million in 2017, it remains a serious public health problem [1]. In 2017, an estimated 5.4 million children under the age of five died worldwide. This translates into 15,000 deaths per day. Sub-Saharan Africa (SSA) continues to be the region with the highest underfive mortality rate (76 deaths per 1000 live births in 2017 ) in the world $[1,2]$. According to the 2019 Ethiopian Mini Demographic and Health Survey (EMDHS) report, under-five mortality in Ethiopia was 55 deaths per 1000 live births [3]. More than half of early childhood deaths are due to diseases that could be easily prevented or treated with simple and affordable interventions, such as administering vaccines $[2,4]$.

Vaccination is one of the most cost-effective means of public health interventions to prevent deaths from childhood infectious diseases. Currently, vaccination prevents 2-3 million deaths annually. An additional 1.5 million deaths could be totally avoided through vaccination [5]. In developing countries, about $16 \%$ of under-five deaths are attributed to vaccine-preventable diseases [6]. In Ethiopia, vaccine-preventable diseases such as pneumonia and diarrheal disease are the leading causes of under-five mortality [7]. Despite the benefits abovementioned, approximately 19.4 million infants worldwide were not reached by immunization services in 2018. The total number of unvaccinated children, $60 \%$ lived in 10 countries: Angola, Brazil, the Democratic Republic of the Congo, Ethiopia, India, Indonesia, Nigeria, Pakistan, the Philippines, and Vietnam [8]. According to the 2019 EMDHS report, only 43\% of Ethiopian children aged 12-23 months were fully vaccinated [3].

The World Health Organization (WHO) launched the Expanded Programme on Immunization (EPI) in 1974, intending to provide universal access to all relevant vaccines for all at risk [9]. EPI in Ethiopia was started in 1980, with a plan to reach $100 \%$ coverage in 1990 [10]. The Ethiopian government mobilized the volunteer Women's Development Army or volunteers, health extension workers (HEWs), and health facilities to achieve universal immunization coverage [7, 11]. likewise, the immunization coverage in Ethiopia increased from $14.3 \%$ in 2000 to $43 \%$ in 2019 [3, 12]. To improve vaccination coverage by implementing different effective interventions, comprehensive nationwide evidence is vital. In Ethiopia, despite many fragmented studies that have been reported so far, a study representing the national and regional immunization coverage is lacking. The reasons mentioned above triggered us to conduct this comprehensive review to summarize the available evidence on routine immunization in Ethiopia. Thus, this review is intended to estimate the national coverage of childhood immunization in Ethiopia. Results obtained from this review will help health policymakers to design evidence-based public health responses.

\section{Methods}

\section{Data source and searches}

This review was reported according to the Preferred Reporting Items for Systematic Review and MetaAnalysis (PRISMA) guideline [13] (Supplementary 1). To find potentially relevant studies, we systematically searched five major databases (i.e., PubMed/MEDLINE, CINAHL, EMBASE, Google Scholar, and Science Direct). Additionally, the reference lists of eligible studies were checked for additional articles. The search was conducted by two authors (DBK and AA) independently. Studies identified through systematic search were retrieved and managed using Endnote X7. The search from the above mentioned databases was conducted using the following terms: "immunization" OR "vaccination" AND "children" OR "childhood" AND "Ethiopia". The search was started in September 2019.

\section{Study selection criteria \\ Inclusion Criteria \\ Design: Community based cross-sectional studies \\ Study setting: Ethiopia \\ Population: Children aged 12-23 months \\ Publication status: All published and unpublished articles \\ Language: English language \\ Publication date: Published from the 1st of January 2000 to the 20th of November, 2019}

\section{Exclusion criteria}

Articles that were not fully accessed after at least two email contacts of the principal investigator were excluded.

\section{Screening process}

We included all community based cross-sectional studies. All titles/abstracts identified in the electronic databases were screened by 2 authors (DBK, AA) independently of one another. Discrepancies were resolved by discussion. All potentially relevant full texts were screened by 2 authors (DBK, AA) independently of one another. Discrepancies were resolved by discussion. In the case of discrepant judgements, a third author (AAA) was involved.

\section{Data extraction process and quality assessment}

Six authors (AAA, MAA, KYC, MA, MYB, and YMA) independently performed data extraction using a predefined eligibility criterion to ensure consistency. The 
data extraction form was prepared using a Microsoft $\mathrm{ft}^{\mathrm{tw}}$ Excel spreadsheet. Disparities between authors were resolved through discussion once the source of disagreements were identified. The following information were extracted from each primary article: number of children with full vaccination, proportion of full vaccination, study location, region, publication year, study design, sample size, and first author (Supplementary file 2).

The quality of included studies was appraised using the Newcastle-Ottawa Quality assessment scale (NOQAS) [14]. The quality of each study was assessed using the following criteria: representativeness of the study, adequate sample size, acceptable non-response rate, used validated measurement tool, comparability of the study, description of outcome assessment, and used appropriate statistical tests. Articles with a global rating score $\geq$ seven out of 10 were considered to be high quality $[15,16]$ (Supplementary file 3).

\section{Outcome variable}

Full vaccination coverage (\%) was the primary outcome measure of this study. According to $\mathrm{WHO}$, a child is considered fully vaccinated after receiving (i) one dose of Bacille Calmette-Guerin (BCG); (ii) three doses of oral polio vaccine (OPV); [diphtheria, pertussis (whooping cough), and tetanus (DPT)], hepatitis B vaccines (HBV), and (iii) one dose of measles vaccine; all before attaining 1 year $[17,18]$. We included studies that fulfilled the above definition. However, we found studies included other vaccines such as rota virus, pneumococcal conjugate, and Hib in their immunization schedules. In such case, we carefully checked the compliance with the above mentioned case definition before considering for our analysis.

\section{Heterogeneity and publication bias}

The presence of statistical heterogeneity within the included studies was checked using I-square statistics and Cochran's-Q test. Accordingly, heterogeneity was classified as low, moderate, or high when the values of Isquare were 25,50 , and $75 \%$, respectively [19]. Additionally, the dispersion of individual results in the forest plot was also used to evaluate the presence of heterogeneity visually. Egger's weighted regression test at a $p$-value < 0.05 was used to assess the presence of publication bias [20].

\section{Data synthesis}

Relevant data from each primary study were extracted using a Microsof ${ }^{\text {tm }}$ Excel form. Then, the data were exported to Stata $^{\mathrm{Tm}}$ Version 14.1 software for further analysis. The overall pooled estimate was computed using metaprop stata command. The standard errors were calculated from the reported estimates and population denominators using a binominal distribution assumption. A random effects meta-analysis model was computed using the DerSimonian and Laird Method [21]. Further statistical analyses such as subgroup analyses, meta-regression were performed to identify the possible sources of heterogeneity. We performed a subgroup analysis based on geographical regions of the country. Furthermore, sensitivity analysis using a random effects model was performed to assess the influence of a single study on the overall pooled estimate. At last, results were presented in tables and forest plots.

\section{Results}

\section{Search results and study selection}

The online search yielded 851 results. Then, after removal of duplicates using EndNote $\times 7$, studies were screened for title and abstract. a. Finally, 23 full texts were retrieved and downloaded to be assessed using our inclusion criteria. Reasons for exclusion of articles were outlined in Fig. 1. From these 23 full-texts, two EDHS based articles were excluded [22, 23]. Because EDHS reports were crude and governmental surveys and due to political instability the report may produce poor quality evidence. In addition, owing to instability in different regions of the country, particular regions were excluded from the survey by the government. As a result, EDHS reports lacks representativeness.

\section{Characteristics of eligible studies}

As presented in Table 1, 21 studies met the inclusion criteria and were included. All the included articles were community based cross-sectional studies. All included studies were published between January 2000 and November 2019. The median year of publication was 2015 . A total of 12,094 (mean $=576$ children) children were included in this review. Of these 21 studies included in the meta-analysis, nine reported the mean age of the study children [24, 25, 28, 30, 31, 33, 34, 39, 42]. Based on the nine studies, the mean age ranged from $16.39[31,42]$ to 18 [34] months.

The smallest $(n=173)$ and largest $(n=923)$ sample sizes were reported from studies done in the Southern Nation's, Nationalities', and People's Region (SNNPR) $[28,36]$. Likewise, the lowest $(20.6 \%)$ vaccination coverage was reported from Afar Region [44] whereas the highest (83.1\%) prevalence of vaccination coverage was reported from Amhara Region [40]. Geographically, nine studies were undertaken in Amhara Region [24, 25, 27, $31,32,37,38,40,41]$, five in the SNNPR $[28,34-36$, 39], three in Oromia Region [30, 33, 42], and one in each in Tigray Region [43], Addis Ababa [29], Somali Region [26], and Afar Region [44]. However, we did get studies from Benishangul Gumuz Region, Dire-Dawa City Administration, Harari Region, and Gambella Region. This 


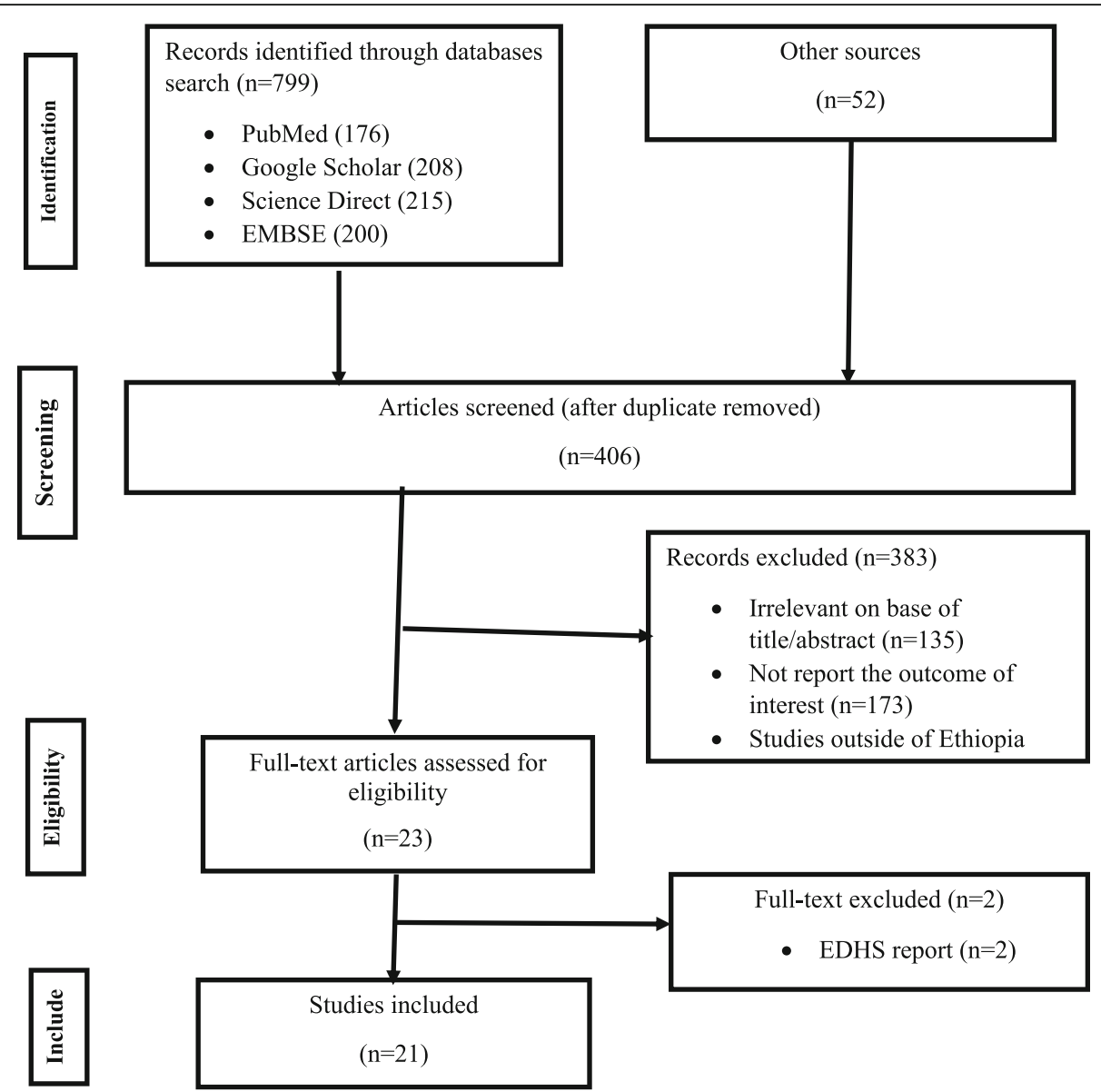

Fig. 1 PRISMA flow diagram which shows the selection of included studies for full vaccination coverage among children aged 12-23 months in Ethiopia, from 2000 to 2019

showed that majority of the researches were undertaken in Amhara Region. The quality score of included studies ranged from eight to 10 , with a mean quality score of 9.71 (SD \pm 0.421 ) (Supplementary file 3). Overall, studies with a quality score of $\geq$ seven were considered as highquality. Lastly, all the 21 included articles were categorized as high-quality studies $[15,16]$.

\section{Pooled full vaccination coverage in Ethiopia}

The overall pooled estimate of full vaccination coverage among children aged 12-23 months in Ethiopia was found to be $60 \%$ (95\% CI: 51, 69\%) (Fig. 2). Regional subgroup analyses revealed that the highest (73, 95\% CI: $67,79 \%)$ proportion of full vaccination coverage was found in Amhara Region; followed by Addis Ababa (72, 95\% CI: 69, 76\%), and SNNPR (53, 95\% CI: 33, 72\%). Conversely the lowest (21, 95\% CI: $18,24 \%)$ vaccination coverage was observed in Afar Region (Table 2). As shown in Fig. 3, the proportion of full vaccination coverage among children before 2015 was 48\% (95\% CI: 33, 64\%), whereas it was 68\% (95\% CI: 59, 77\%) after 2015.

\section{Meta regression and publication bias}

Random-effects meta-regression was conducted by considering year of publication and sample size as covariates. The analysis indicated that heterogeneity was not explained by sample size $(p=0.443)$ and publication year $(p=0.117) \quad$ (Table 3). Funnel plot asymmetry was assessed using Egger's weighted regression test to examine the presence of publication bias. However, no statistically significant of publication bias was detected $(p=0.822)$ (Fig. 4).

\section{Discussion}

To the best of our knowledge, this systematic review and meta-analysis is the first of its kind to estimate the full vaccination coverage among children aged 12-23 months in Ethiopia. The overall pooled proportion of full vaccination coverage among children in Ethiopia was found to be $60 \%$ (95\% CI: $50,69 \%$ ). This finding is in agreement with the findings of studies conducted in Kenya (57.7\%) [45], Malawi (51\%) [46], and Uganda (68\%) [47]. However, our finding is higher than the 
Table 1 Descriptive summary of 21 included studies in the systematic review and meta-analysis of full immunization coverage among children aged 12-23 months in Ethiopia, from 2000 to 2019

\begin{tabular}{|c|c|c|c|c|c|c|}
\hline First Author & Year & Location (Region) & Study area & Mean age (Months) & Sample size & Coverage of fully Vaccination (\%) \\
\hline Debie A [24] & 2014 & Amhara & Mecha District & 17.5 & 497 & 49.3 \\
\hline Girmay A [25] & 2019 & Amhara & Sekota Zuria & 16.7 & 620 & 77.4 \\
\hline Mohamud AN [26] & 2014 & Somali Region & Jigjiga & - & 582 & 36.6 \\
\hline Tenaw G [27] & 2017 & Amhara & Debre Markos & - & 288 & 91.7 \\
\hline Hailu S [28] & 2019 & SNNPR & Wonago & - & 923 & 63.4 \\
\hline Tolera D [29] & 2014 & Addis Ababa & Addis Ketema sub-city & - & 585 & 72.4 \\
\hline Legesse E [30] & 2015 & Oromia & Sinana District & 17.9 & 591 & 76.8 \\
\hline Tesfaye TD [31] & 2018 & Amhara & East Gojjam & 16.39 & 830 & 58.4 \\
\hline Okwaraji YB [32] & 2012 & Amhara & Dabat District & - & 775 & 81.7 \\
\hline Etana B [33] & 2012 & Oromia & Ambo Woreda & 16.8 & 536 & 36.0 \\
\hline Meleko A [34] & 2017 & SNNPR & Bench Maji Zone & 18 & 322 & 42.2 \\
\hline Ayano B [35] & 2015 & SNNPR & Hosanna Town & - & 508 & 30.5 \\
\hline Fite RO [36] & 2019 & SNNPR & Areka Town & - & 173 & 75.1 \\
\hline Kassahun MB [37] & 2015 & Amhara & Lay Armachiho District & - & 751 & 76.0 \\
\hline Mekonnen AG [38] & 2019 & Amhara & Minjar-Shenkora District & - & 566 & 75.6 \\
\hline Animaw W [39] & 2014 & SNNPR & Arba Minch Town & 17.4 & 630 & 73.2 \\
\hline Ebrahim T [40] & 2015 & Amhara & Tehuledere District & - & 539 & 83.1 \\
\hline Lake MW [41] & 2015 & Amhara & Dessie Town & - & 724 & 65.2 \\
\hline Mohammed H [42] & 2013 & Oromia & East Hararghe Zone & 16.39 & 694 & 22.9 \\
\hline Kidane T [43] & 2000 & Tigray & Mekele & - & 220 & 51.0 \\
\hline Beyene E [44] & 2013 & Afar & Afar,Zone 3 & - & 740 & 20.6 \\
\hline
\end{tabular}

SNNPR South Nations and Nationalities People of the Region

vaccine coverage proportions presented in the 2011 EDHS (24\%), the 2016 EDHS (39\%), and the 2019 EMDHS (43\%) reports [3, 23, 48]. The above differences could be elucidated by the fact that the demographic and health surveys were conducted in different segments of the country; which contained data from children live in rural and urban areas. However, in our meta-analysis only community based cross-sectional studies were included. Similarly, our estimate is also higher compared to reports from Nigeria (34.4\%) [49], India (39\%) [50], and Brazil (47\%) [51]. These discrepancies might be due to differences in data generating methods, and the level of government interventions and commitments.

On the other hand, our finding is much more lower than the WHO recommended level ( $\geq 90 \%$ ) [52]. This shortfall in reaching WHO's 90\% target could be due to common challenges facing the immunization program in Ethiopia, such as immunization service interruption due to supply shortages, limited outreach services in hard-to-reach communities, and EPI staff turnover [53].

The subgroup analyses also showed that vaccination coverage across regions of Ethiopia was highly dispersed. The lowest coverage was observed in Afar Region (21\%), while the highest coverage was observed in Amhara Region (73\%). This regional variation is in line with the 2019 EMDHS report [3]. This discrepancy could be explained by differences in the caregiver's educational level as well as differences in socio-cultural and religious backgrounds.

Additionally, the pooled estimate of full vaccination coverage before 2015 was $48 \%$, whereas the pooled estimate of full vaccination coverage after 2015 was $68 \%$. From this finding, we can understand that the proportion of vaccine coverage among children has increased slightly in every consecutive year. This finding implies that the country has been implementing different strategies to improve childhood vaccination coverage. This finding is in parallel with the EDHS surveys conducted over time indicated that the vaccination coverage has increased from $14.4 \%$ in 2000 to $43 \%$ in 2019 [3, 12]. This promising increase in the proportion of full vaccination coverage might be due to improvements in accessibility and provision of immunization services to the wider population. However, since the inclusion period is almost 20 years, children born in 2000 are now adults; therefore, their vaccination coverage may not represent the current childhood vaccination coverage. 


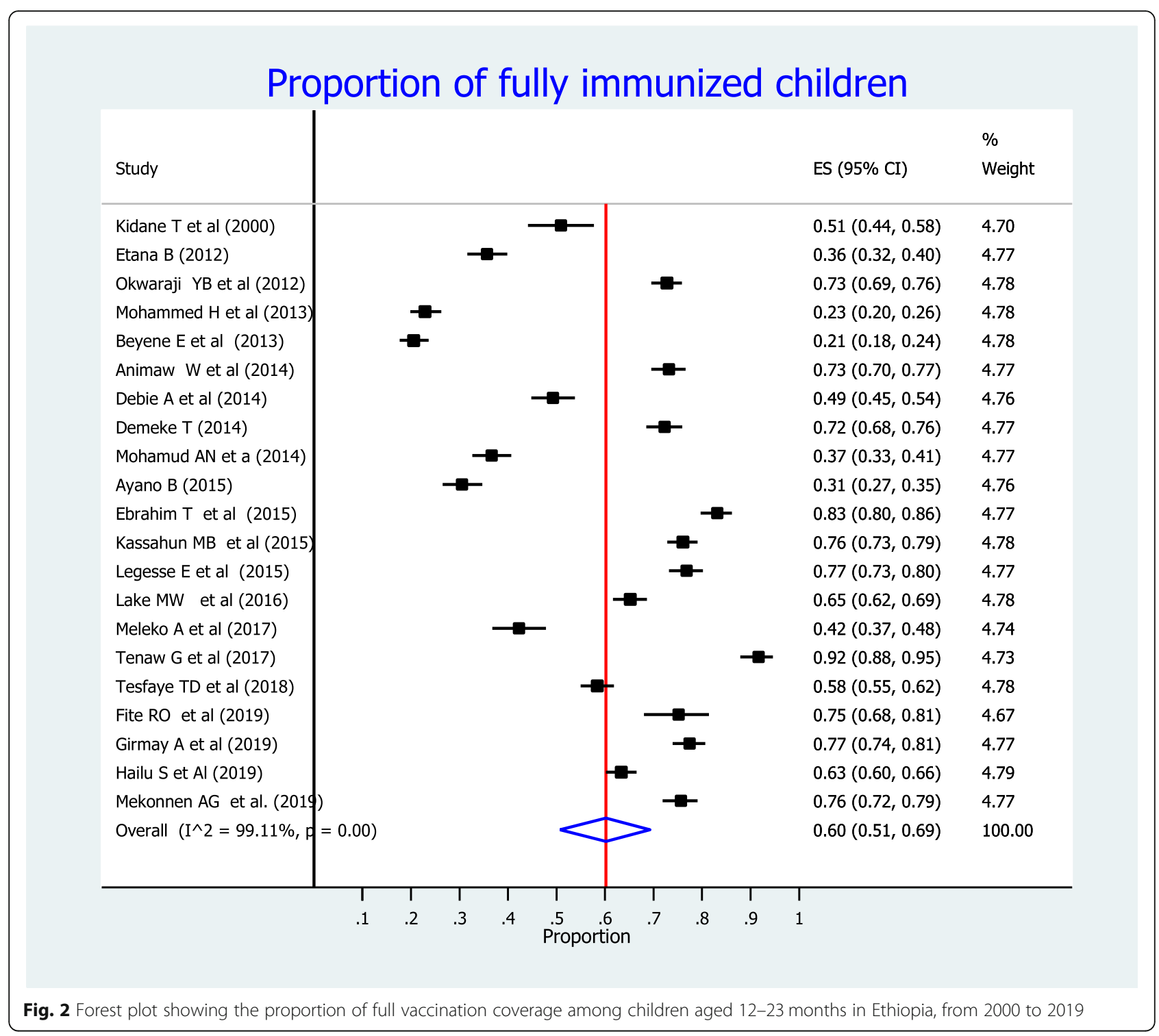

Table 2 Subgroup analysis of full vaccination coverage among children aged 12-23 months by region in Ethiopia, from 2000 to 2019

\begin{tabular}{lll}
\hline S. No & Region & Estimate of full vaccination coverage $[\%(95 \% \mathrm{Cl})]$ \\
\hline 1 & Amhara & $73(67,79)$, \\
2 & Oromia & $28(25,30)$ \\
3 & SNNPR & $53(33,72)$ \\
4 & Somali regional state & $37(33,41)$ \\
5 & Addis Ababa & $72(69,76)$ \\
6 & Tigray & $51(44,57)$ \\
7 & Afar & $21(18,24)$ \\
8 & Overall pooled estimate & $60(51,69)$ \\
\hline
\end{tabular}




\section{Proportion of fully immunized children by time period}

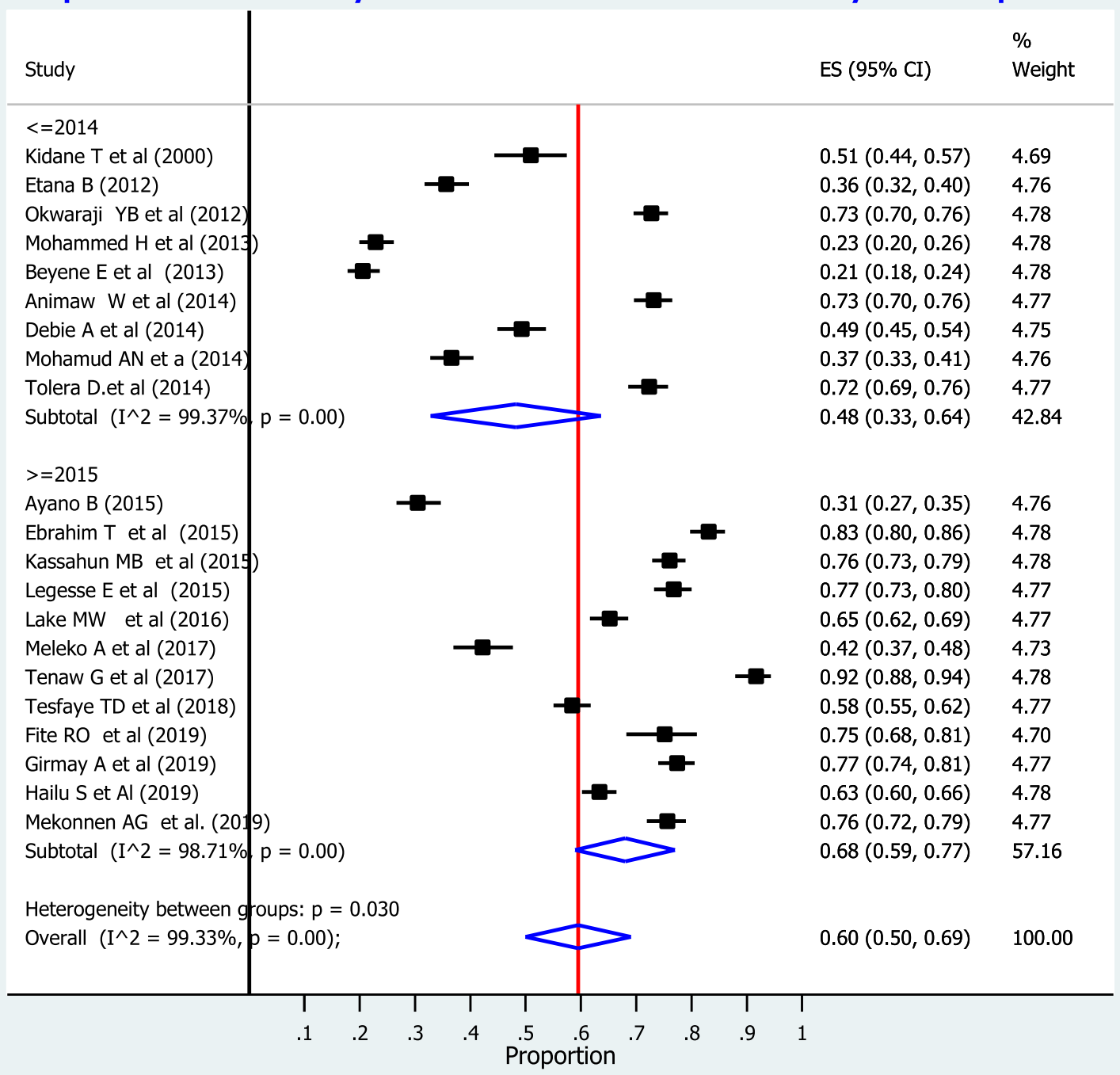

Fig. 3 Forest plot showing the proportion of full vaccination coverage among children aged 12-23 months in Ethiopia, from 2000 to 2019 by time period

Since this included community based cross-sectional studies, the findings can be generalized to the entire population of children aged 12-23 months in Ethiopia. However, our review has some limitations. Firstly, we were unable to find studies conducted in some regions

Table 3 Meta-regressions of the full vaccination coverage among children aged 12-23 months in Ethiopia by sample size, and publication year of included studies

\begin{tabular}{lll}
\hline Covariate & $\beta(95 \% \mathrm{Cl})$ & $P$-Value \\
\hline Publication year & $0.019(-0.005,0.043)$ & 0.117 \\
Sample size & $-0.00019(-0.00069, .000319)$ & 0.443 \\
\hline
\end{tabular}

of the country. Therefore, further community-based studies shall be done in regions such as Benishangul Gumuz, Dire-Dawa City Administration, Harari, and Gambella. Such that not having estimates for them might bias pooled coverage estimates. Since these regions were found far away from the central location of the country and presence of some insurrection, may contribute for lack of evidences for our estimate. Secondly, the current review considered only papers published in English language. At last, some biases might be introduced sine we used the NOS for quality assessment tool. In this tool, some domains were not univocal; and lacked comprehensive definition for each domain. 


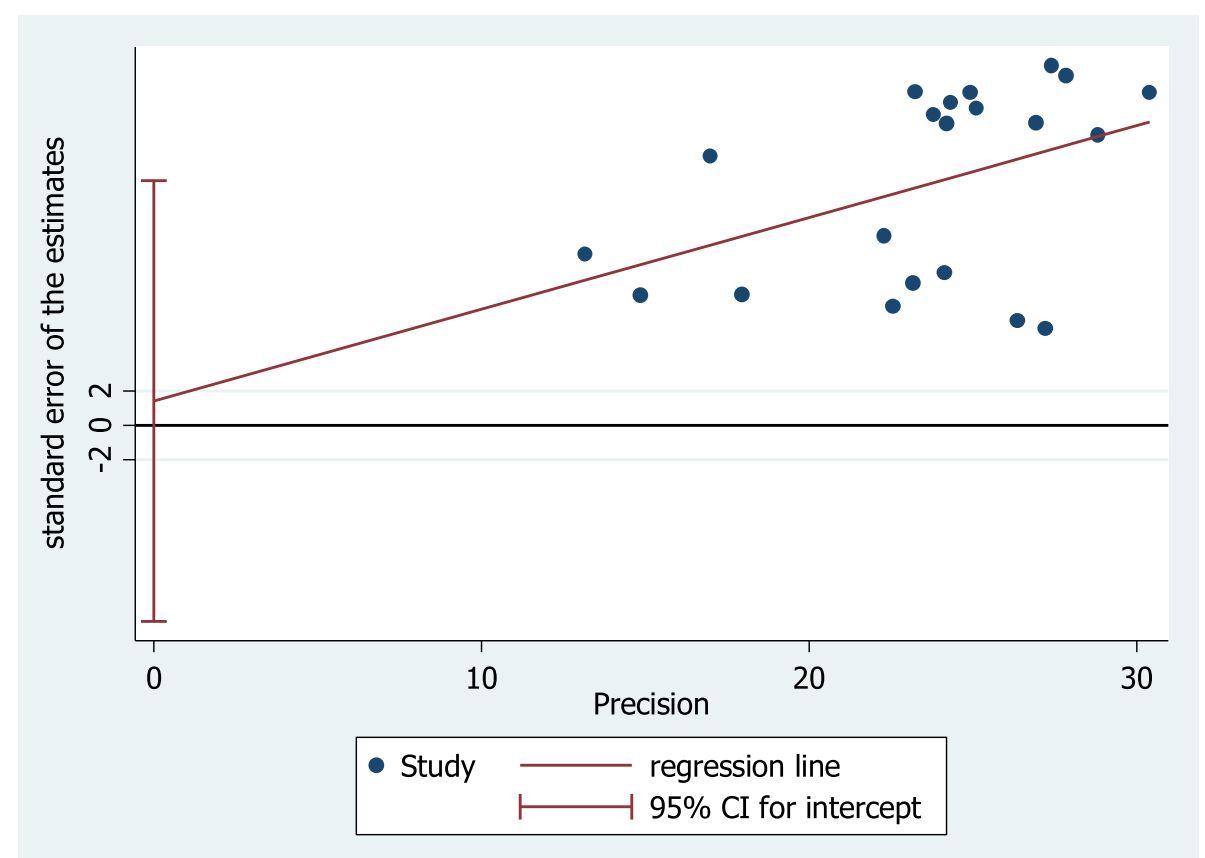

Fig. 4 Funnel plot to check publication bias of the full vaccination coverage among children aged 12-23 months in Ethiopia by sample size, and publication year of included studies

\section{Conclusions}

Our review suggested that six in every 10 children in Ethiopia were fully vaccinated. However, this finding is much lower than the WHO-recommended level ( $\geq$ $90 \%)$. In addition, vaccination coverage among children was highly varied across the regions of the country. Furthermore, in Ethiopia, the vaccine coverage among children has increased slightly in each consecutive year.

Therefore, a special attention should be given to improve the overall childhood vaccination coverage across the country.

\section{Supplementary information}

Supplementary information accompanies this paper at https://doi.org/10. 1186/s12889-020-08940-x.

Additional file 1. PRISMA 2009 checklist.

Additional file 2. Data extraction sheet.

Additional file 3. Newcastle-Ottawa Quality assessment scale (NOQAS).

\section{Abbreviations}

Cl: Confidence Interval; WHO: World Health Organization; MMR: Maternal Mortality Ratio; ANC: Antenatal Care; EPI: Expanded Programme on Immunization; EDHS: Ethiopia Demographic and Health Survey; EMDHS: Ethiopia Mini Demographic and Health Survey; UNICEF: United Nations Children's Fund; SSA: Sub-Saharan Africa

\section{Acknowledgments}

We would like to thank all the primary authors of studies included in this systematic review and meta- analysis.
Availability of the data and materials

All data analyzed for this study are included in the supplementary information files.

\section{Authors' contributions}

DBK originated the research idea and analyzed the data. AA, MAA, MA, YMA, AAA, KYC, and MYB analyzed the data s and reviewed the manuscript. All authors have read and approved the manuscript, and ensure that this is the case.

\section{Funding}

No funding was obtained for this study.

Ethics approval and consent to participate

Not applicable.

Consent for publication

Not applicable.

\section{Competing interests}

The authors declare that they have no competing interests.

\section{Author details}

${ }^{1}$ Department of Public Health, College of Health Sciences, Debre Markos University, P.O. Box 269, Debre Markos, Ethiopia. ${ }^{2}$ Department of Human Nutrition and Food Science, College of Health Sciences, Debre Markos University, Debre Markos, Ethiopia. ${ }^{3}$ School of Public Health, College of Medicine and Health Science, Hawassa University, Hawassa, Ethiopia. ${ }^{4}$ Deprtment of Biomedical Science, School of Medicine, Debre Markos University, Debre Markos, Ethiopia. ${ }^{5}$ College of Health Sciences, Debre Markos University, Debre Markos, Ethiopia. ${ }^{6}$ Department of Nursing, College of Health Sciences, Debre Markos University, Debre Markos, Ethiopia. ${ }^{7}$ Faculty of Health, University of Technology Sydney, Sydney, Australia. 
Received: 2 January 2020 Accepted: 17 May 2020 Published online: 24 May 2020

\section{References}

1. United Nations Department of Economic and Social Affairs: Levels and Trends in Child Mortality Report 2018. Accessed from https://www.un.org/ en/development/desa/population/publications/mortality/child-mortalityreport-2018.asp. 2018.

2. World health Organization: Children: reducing mortality. Accessed from https://www.who.int/news-room/fact-sheets/detail/children-reducingmortality. 2018.

3. Ethiopian Public Health Institute (EPHI)[Ethiopia] and ICF. Ethiopia Mini Demographic and Health Survey 2019: Key Indicators. 2019. [https:// dhsprogram.com/pubs/pdf/PR120/PR120.pdf].

4. World Health Organization: Maternal, newborn, child and adolescent health. Accessed from https://www.who.int/maternal_child_adolescent/documents/ levels_trends_child_mortality_2018/en/. 2018.

5. World health Organization: Ten threats to global health in 2019. Accessed from https://www.who.int/emergencies/ten-threats-to-global-health-in-2019. 2019.

6. Mekasha A, Lemma F, Shiferaw T: Child health problems in Ethiopia; 1995 Accessed from https://www.ejhd.org/index.php/ejhd/article/download/1 080/825/.

7. Federal Ministry of Health. Ethiopia National Expanded Programme on Immunization. Addis Ababa; 2015. Available at http://www nationalplanningcycles.org/sites/default/files/country_docs/Ethiopia/ethiop_ cmyp_latest_revised_may_12_2015.pdf.

8. World health Organization: Immunization coverage. Accessed from https:/ www.who.int/news-room/fact-sheets/detail/immunization-coverage. 2019.

9. World health Organization: The Expanded Programme on Immunization. Accessed from https://www.who.int/immunization/programmes_systems/ supply_chain/benefits_of_immunization/en/. 2013.

10. Kidane T, Yigzaw A, Sahilemariam $Y$, Bulto T, Mengistu H, Belay T, Bisrat F, Benti D, Mbakuliyemo N, Olusegun B. National EPI coverage survey report in Ethiopia, 2006. Ethiop J Health Dev. 2008;22(2):148-57.

11. Central Statistical Agency (Ethiopia): Demographic and Health Survey Key Indicators. Available at https://dhsprogram.com/pubs/pdf/PR81/PR81.pdf. 2016

12. Central Statistical Authority. Ethiopia Demographic and Health Survey 2000, 2001. [https://www.dhsprogram.com/pubs/pdf/FR118/FR118.pdf].

13. Moher D, Liberati A, Tetzlaff J, Altman DG, Group P: Preferred reporting items for systematic reviews and meta-analyses: the PRISMA statement. 2010.

14. Fazel $\mathrm{S}$, Khosla $\mathrm{V}$, Doll H, Geddes J. The prevalence of mental disorders among the homeless in western countries: systematic review and metaregression analysis. PLoS Med. 2008;5(12):e225

15. Islam MM, lqbal U, Walther B, Atique S, Dubey NK, Nguyen P-A, Poly TN, Masud JHB, Li Y-CJ, Shabbir S-A. Benzodiazepine use and risk of dementia in the elderly population: a systematic review and meta-analysis. Neuroepidemiology. 2016;47(3-4):181-91.

16. Leshargie $C T$, Alebel A, Kibret GD, Birhanu MY, Mulugeta $H$, Malloy $P$, Wagnew F, Ewunetie AA, Ketema DB, Aderaw A. The impact of peer pressure on cigarette smoking among high school and university students in Ethiopia: A systemic review and meta-analysis. PLoS One. 2019;14:10.

17. Okwo-Bele J-M, Cherian T. The expanded programme on immunization: a lasting legacy of smallpox eradication. Vaccine. 2011;29:D74-9.

18. Organization WH: Global vaccine action plan 2011-2020. 2013.

19. Rücker G, Schwarzer G, Carpenter JR, Schumacher M. Undue reliance on I 2 in assessing heterogeneity may mislead. BMC Med Res Methodol. 2008;8(1):79.

20. Barendregt JJ, Doi SA, Lee YY, Norman RE, Vos T. Meta-analysis of prevalence. J Epidemiol Community Health. 2013:67(11):974-8.

21. DerSimonian R, Laird N. Meta-analysis in clinical trials. Control Clin Trials. 1986;7(3):177-88.

22. Tamirat KS, Sisay MM. Full immunization coverage and its associated factors among children aged 12-23 months in Ethiopia: further analysis from the 2016 Ethiopia demographic and health survey. BMC Public Health. 2019; 19(1):1019.

23. Abadura SA, Lerebo WT, Kulkarni U, Mekonnen ZA. Individual and community level determinants of childhood full immunization in Ethiopia: a multilevel analysis. BMC Public Health. 2015;15(1):972.

24. Debie A, Taye B. Assessment of fully vaccination coverage and associated factors among children aged 12-23 months in Mecha District, north West Ethiopia: a cross-sectional study. Sci J Public Health. 2014;2(4):342-8.
25. Girmay A, Dadi AF. Full immunization coverage and associated factors among children aged 12-23 months in a hard-to-reach areas of Ethiopia. Int J Pediatr. 2019;2019:1924941.

26. Mohamud AN, Feleke A, Worku W, Kifle M, Sharma HR. Immunization coverage of 12-23 months old children and associated factors in Jigjiga District, Somali National Regional State, Ethiopia. BMC Public Health. 2014; 14(1):865

27. Gualu T, Dilie A. Vaccination coverage and associated factors among children aged 12-23 months in debre markos town, Amhara regional state, Ethiopia. Adv Pub Health. 2017;2017:5352847.

28. Hailu S, Astatkie A, Johansson KA, Lindtjørn B. Low immunization coverage in Wonago district, southern Ethiopia: A community-based cross-sectional study. PLoS One. 2019;14(7):e0220144.

29. Tolera D. Assessment of magnitude and factors associated with fullimmunization coverage in children aged 12-23 months in Addis Ketema sub-city, Addis Ababa, Ethiopia. Addis Ababa: Institutional Repository; 2014.

30. Legesse $\mathrm{E}$, Dechasa W. An assessment of child immunization coverage and its determinants in Sinana District, Southeast Ethiopia. BMC Pediatr. 2015; 15(1):31.

31. Tesfaye TD, Temesgen WA, Kasa AS. Vaccination coverage and associated factors among children aged 12-23 months in Northwest Ethiopia. Hum Vaccines Immunother. 2018;14(10):2348-54.

32. Okwaraji YB, Mulholland $K$, Schellenberg J, Andarge G, Admassu M, Edmond $\mathrm{KM}$. The association between travel time to health facilities and childhood vaccine coverage in rural Ethiopia. A community based cross sectional study. BMC Pub Health. 2012;12(1):476.

33. Etana B, Deressa W. Factors associated with complete immunization coverage in children aged 12-23 months in ambo Woreda, Central Ethiopia. BMC Public Health. 2012;12(1):566.

34. Meleko A, Geremew M, Birhanu F. Assessment of child immunization coverage and associated factors with full vaccination among children aged 12-23 months at Mizan Aman town, bench Maji zone, Southwest Ethiopia. Int J Pediatr. 2017;2017:7976587.

35. Ayano B. Factors affecting fully immunization status of children aged 12-23 months in Hosanna Town, South Ethiopia. J Pregnancy Child Health. 2015:2:185.

36. Fite RO, Hailu LD. Immunization coverage of 12 to 23 months old children in Ethiopia; 2019.

37. Kassahun MB, Biks GA, Teferra AS. Level of immunization coverage and associated factors among children aged 12-23 months in lay Armachiho District, North Gondar zone, Northwest Ethiopia: a community based cross sectional study. BMC Res Notes. 2015;8(1):239.

38. Mekonnen AG, Bayleyegn AD, Ayele ET. Immunization coverage of 12-23 months old children and its associated factors in Minjar-Shenkora district, Ethiopia: a community-based study. BMC Pediatr. 2019;19(1):198.

39. Animaw W, Taye W, Merdekios B, Tilahun M, Ayele G. Expanded program of immunization coverage and associated factors among children age 12-23 months in Arba Minch town and Zuria District, southern Ethiopia, 2013. BMC Public Health. 2014;14(1):464.

40. Ebrahim Y, Salgedo WB. Childhood immunization coverage in Tehulederie district, northeast of Ethiopia: a community based cross sectional study. Int J Curr Res. 2015;7(9):20234-40.

41. Lake MW, Boulanger L, Wasswa $P$, Merbratu M, Fenta A. Factors for low routine immunization performance: a community-based cross-sectional study in Dessie town, south Wollo zone, Ethiopia, 2014. Adv Appl Sci. 2016; $1(1): 7-17$

42. Mohammed $\mathrm{H}$, Atomsa A. Assessment of child immunization coverage and associated factors in Oromia regional state, eastern Ethiopia. Sci Techno Arts Res J. 2013:2(1):36-41.

43. Kidane T, Tekie M. Factors influencing child immunization coverage in a rural district of Ethiopia, 2000. Ethiop J Health Dev. 2003;17(2):105-10.

44. Beyene E, Worku A, Bisrat F, Fantahun M. Factors associated with immunization coverage among children age 12-23 months: the case of zone 3, Afar regional state, Ethiopia. Ethiop Med J. 2013:51:41-50.

45. Kitui J, Lewis S, Davey G. Factors influencing place of delivery for women in Kenya: an analysis of the Kenya demographic and health survey, 2008/2009. BMC Pregnancy Childbirth. 2013;13(1):40.

46. Munthali AC. Determinants of vaccination coverage in Malawi: evidence from the demographic and health surveys. Malawi Med J. 2007;19(2):79-82.

47. Odiit $A$, Amuge $B$. Comparison of vaccination status of children born in health units and those born at home. East Afr Med J. 2003;80(1):3-6. 
48. Lakew Y, Bekele A, Biadgilign S. Factors influencing full immunization coverage among 12-23 months of age children in Ethiopia: evidence from the national demographic and health survey in 2011. BMC Public Health. 2015:15(1):728.

49. Adeloye D, Jacobs W, Amuta AO, Ogundipe O, Mosaku O, Gadanya MA, Oni G. Coverage and determinants of childhood immunization in Nigeria: a systematic review and meta-analysis. Vaccine. 2017;35(22):2871-81.

50. Banerjee AV, Duflo E, Glennerster R, Kothari D. Improving immunisation coverage in rural India: clustered randomised controlled evaluation of immunisation campaigns with and without incentives. BMJ. 2010;340:c2220.

51. Barreto TV, Rodrigues LC. Factors influencing childhood immunisation in an urban area of Brazil. J Epidemiol Community Health. 1992;46(4):357-61.

52. Diphtheria-tetanus-pertussis WHO. (DPT3) immunization coverage. 2018 [https://www.who.int/news-room/fact-sheets/detail/immunization-coverage].

53. Fact sheet [http://www.moh.gov.et/ejcc/sites/default/files/2019-10/Final\%2 0EPI\%20Fact\%20sheet.pdf].

\section{Publisher's Note}

Springer Nature remains neutral with regard to jurisdictional claims in published maps and institutional affiliations.

Ready to submit your research? Choose BMC and benefit from:

- fast, convenient online submission

- thorough peer review by experienced researchers in your field

- rapid publication on acceptance

- support for research data, including large and complex data types

- gold Open Access which fosters wider collaboration and increased citations

- maximum visibility for your research: over $100 \mathrm{M}$ website views per year

At $\mathrm{BMC}$, research is always in progress.

Learn more biomedcentral.com/submissions 